\title{
Measuring and modelling risk
}

\author{
David E. Allen
}

School of Accounting, Finance and Economics, Edith Cowan University, Joondalup Campus, 270 Joondalup Drive,

Joondalup, Western Australia

E-mail: d.allen@ecu.edu.au

\begin{abstract}
This paper will examine some commonly adopted approaches to the measurement of risk in finance and the various shortcomings implicit in the underpinnings of these approaches: early views on the nature of risk and uncertainty (Hume, Bernoulli, Knight, Keynes and Ramsey); the adoption of a mean variance decision choice criteria as a central foundation in financial economics and its accompanying limitations; the various approaches in financial econometrics to modelling volatility $(\mathrm{ARCH}, \mathrm{GARCH}$, stochastic volatility, realised volatility and attempts to capture 'tail risk'); the measurement of risk implicit in applications of option pricing models and implied volatility (in particular the VIX index); the Basel Agreements and convention of modelling risk in a value at risk (VaR) framework; and the attractions of conditional value at risk ( $\mathrm{CVaR})$ as an alternative metric. I shall conclude with a consideration of the shortcomings of these various approaches when faced with a system wide shock as recently experienced in the global financial crisis.
\end{abstract}

Keywords: risk measurement; mean-variance risk analysis; financial econometrics; VaR; CVaR.

Reference to this paper should be made as follows: Allen, D.E. (2009) 'Measuring and modelling risk', Global Business and Economics Review, Vol. 11, Nos. 3/4, pp.199-224.

Biographical notes: David E. Allen is a Professor of Finance at Edith Cowan University, Perth, Western Australia. He is the author and co-author of three books and monographs and over 70 refereed publications on a diverse range of topics covering corporate financial policy decisions, asset pricing, business economics, funds management and performance bench-marking, volatility modelling and hedging, and market microstructure and liquidity.

\section{Introduction}

This paper is concerned with contemporary approaches to modelling risk that predominate in the finance and financial econometrics literature as well as in applications in the investment and financial services industry and via financial regulation, vis-à-vis Basel 11. This view of risk and belief that it can be quantified effectively is relatively 'recent'. It can be contrasted with earlier views on the topic. 
For example, according to Wikipedia: The term risk only emerged relatively recently. "In the Middle Ages the term riscium was used in highly specific contexts, above all in the sea trade and in its ensuing legal problems of loss and damage." In the 16th Century the vernacular use of rischio was derived from the Arabic word 'قزر', 'rizk', meaning 'to seek prosperity'. It was introduced to European usage by North African trading links. The term risk appeared in the English language in the 17th Century imported from Europe and eventually usage moved away from the concept of good and bad fortune to the more modern usage but even during the 20th Century the concept had a number of interpretations and meanings. Nevertheless, much of the modern usage has its origins in the Enlightenment in the work of Hume and Bernoulli, as will be discussed below.

The paper is divided into several sections; a brief introduction broaching some early thoughts on risk is followed by section three on the foundations of risk in financial economics; this considers the work of Hume and Bernouilli from the 18th century, and Knight, Keynes and Ramsey from the 20th century. Section four considers modern finance and risk; Markowitz and the development of portfolio theory in particular. Section five considers risk modelling in financial econometrics plus implied volatility and the recent regulatory embrace of value at risk (VaR). The brief review covers the $\mathrm{ARCH} / \mathrm{GARCH}$ literature, stochastic volatility models, realised volatility, and implied volatility and the use of the VIX index, value at risk (VaR), conditional value at risk (CVaR) and the results of assessments of volatility forecasting. The final section considers the onset of the global financial crisis, some of the triggers in the US housing market and why the above models failed to predict these events.

\section{Earlier thoughts on risk}

Risk, in the modern applications of the concept, may be contrasted with the more common earlier focus on luck; which might be viewed as phenomena or occurrences that are beyond a person's control. For example a form of luck might be genetic endowment or circumstances of birth; which would represent constitutional luck that cannot be changed. Yet another form of luck is circumstantial luck, the haphazard favourable congruence of circumstances. This might be represented by the traffic jam that causes you to be late and to miss the flight that subsequently crashes. Such luck may also only be apparent in hindsight; if you had not been delayed you would not have missed the fatal flight. Risk is not viewed as being synonymous with good fortune.

The term risk is defined variously in different contexts but it is frequently employed to refer to unfavourable consequences which may eventuate. One usage is illustrated by the statement that 'drink driving may increase risk of fatal accidents'. Risk might be interpreted as the cause of the unwanted event; driving over the limit increases the risk of traffic accidents. Risk may also be used to refer to the probability of an unwanted event. Driving under the influence of drink increases the risk of accident; for example statements such as $32 \%$ of fatal accidents involve drink/driving. It may be used to refer to the expected probability of an unwanted event. If you drink/drive there is a $20 \%$ increase in the probability of an accident. Many of these usages have their origins in 18th Century thought. 


\section{Foundations for the treatment of risk in financial economics}

\subsection{The work of David Hume}

David Hume in A Treatise on Human Nature, first published in parts in 1739 and 1740, writes in Section 11; on 'Of probability, and of the idea of cause and effect'. In this section he talks of three important relations, identity, the situations in time and place, and causation. He argues that we may "consider the relation of contiguity as essential to that of causation; one object is associated with another, priority of time in the cause before the effect". [This was later taken up in a time series econometrics sense by Clive Granger 1969) in his concept of Granger causality]. However, Hume then cautions that belief in causality comes from observation; "since it is not from knowledge or any scientific reasoning, that we derive the opinion of the necessity of a cause to every new production, that opinion must necessarily arise from observation and experience".

He continues to suggest that the concept of a causal connexion or relation between pairs of objects, which can lead us beyond the immediate impressions of our memory and senses, as that of cause and effect is an idea that is derived from experience. This prior experience informs us that: "this pair of objects, in all past instances, have been constantly conjoined with each other: And as an object similar to one of these is supposed to be immediately present in its impression, we thence presume on the existence of one similar to its usual attendant". He then adds that "probability is founded on the presumption of a resemblance betwixt those objects, of which we have had experience, and those, of which we have had none". He then suggests that: "One would appear ridiculous, who would say, that it is only probable the sun will rise to-morrow, or that all men must dye; though it is plain we have no further assurance of these facts, than what experience affords us". He suggests that human reason can be distinguished into three kinds: "viz. That from knowledge, from proofs, and from probabilities".

Prior experience leads us to take a view on likely outcomes: "Should it be said, that though in an opposition of chances it is impossible to determine with certainty, on which side the event will fall, yet we can pronounce with certainty, that it is more likely and probable, it will be on that side where there is a superior number of chances, than where there is an inferior." He concludes that the supposition that the future resembles the past is derived from habit, based on past experience.

\subsection{Nicholas Bernouilli: another 18th century antecedent}

Justification for a subjective view of probability was provided by Nicholas Bernoulli in 1738. Bernouilli suggests that;

"Ever since mathematicians first began to study the measurement of risk there has been general agreement on the following proposition: Expected values are computed by multiplying each possible gain by the number of ways in which it can occur, and then dividing the sum of these products by the total number of possible cases where, in this theory, the consideration of cases which are all of the same probability is insisted upon."

Bernouilli continues that;

"the determination of the value of an item must not be based on its price, but rather on the utility it yields. The price of the item is dependent only on the 
thing itself and is equal for everyone; the utility, however, is dependent on the particular circumstances of the person making the estimate".

Bernoulli developed expected utility theory as a decision criterion under conditions of risk.

Figure 1 Bernouilli's expected utility of outcomes

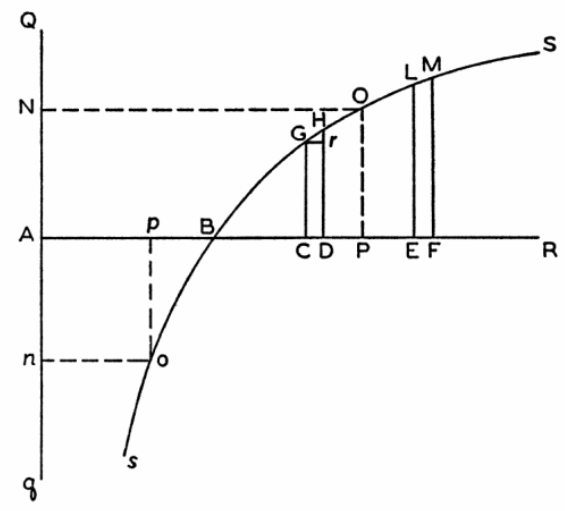

Therefore, let $\mathrm{AB}$ represent the quantity of goods initially possessed. Then after extending $\mathrm{AB}$, a curve BGLS must be constructed, whose ordinates CG, DH, EL, FM, etc., designate utilities corresponding to the abscissas $\mathrm{BC}, \mathrm{BD}, \mathrm{BE}, \mathrm{BF}$, etc., designating gains in wealth. Further, let m, n, p, q, etc., be the numbers which indicate the number of ways in which gains in wealth $\mathrm{BC}, \mathrm{BD}, \mathrm{BE}, \mathrm{BF}$ [misprinted in the original as $\mathrm{CF}$, etc., can occur. Then ... the moral expectation of the risky proposition can be calculated as

$$
P O=\frac{m \cdot C G+n \cdot D H+p \cdot E L+q \cdot F M+\cdots}{m+n+p+q+\cdots}
$$

Bernouilli also discusses the benefits of diversification. He suggests that if Sempronius owns goods at home worth a total of 4,000 ducats and in addition possesses 8,000 ducats worth of commodities in foreign countries from where they can only be transported by sea. Yet, experience suggests that one in ten ships is wrecked at sea, then given these conditions if Sempronius trusted all his 8,000 ducats of goods to one ship his expectation of the commodities would be worth 6,751 ducats, calculated as:

$$
\sqrt[10]{1,200^{9} 4,000^{1}}-4,000
$$

If, however, he were to trust equal portions of these commodities to two ships the value of his expectation would be:

$$
\sqrt[100]{12,000^{81} \cdot 8,000^{18} \cdot 4,000}-4,000, \text { in effect } 7,033 \text { ducats }
$$

The above is an analysis of the benefits of diversification, minus the treatments of covariances introduced by Markowitz. Bernouilli's expected utility theory was subsequently adopted by John von Neumann and Oskar Morgenstern who reinterpreted and presented an axiomatisation of the same theory in 1944. This is often referred to as von Neumann-Morgenstern utility. 
A direct link can be drawn from the work of Bernoulli to that of Harry Markowitz and the development of modern portfolio theory.

\subsection{Keynes and objective probabilities}

Holton (2004) argues that the work of Hume precedes two main strands in 20th Century thinking about risk: subjective probability and 'operationalism'. The former suggests that beliefs about probability summarise individual calculations but are not scientific, or independently verifiable. They are specifications of individual degrees of belief. Keynes (1921) took the view that probabilities are 'rationally determinate'.

"Part of our knowledge we obtain direct; and part by argument. The theory of probability is concerned with the part which we obtain by argument, and it treats of the different degrees in which the results so obtained are conclusive or inconclusive".

For Keynes; "The terms certain and probable describe the various degrees of rational belief about a proposition which different amounts of knowledge authorize us to entertain". Furthermore; "The theory of probability is logical, therefore, because it is concerned with the degree of belief which it is rational to entertain in given conditions, and not merely with the actual beliefs of individuals, which may or may not be rational". He further adds that if our premises consist of a set of propositions $h$, and our conclusion consists of any set of propositions $a$, then if a knowledge of $h$ justifies a rational belief in a of degree $a$, we say there is a probability relation of degree $a$ between $a$ and $h$. He then sets out four alternatives: first there may be situations in some sense in which there is no probability at all; or second, probabilities might not all belong to a single set of magnitudes measurable in terms of common units; or third, these measures may always exist, but in many cases are, and must remain, unknown. Finally, probabilities may belong to this type of set and their measures are potentially capable of being determined by us, although we are not always able so to determine them in practice.

He talks of Laplace's suggested ordering of probabilities between 0 and 1. It is a matter of lack of evidence of lack of skill in utilising the evidence available? What do we mean by unknown - unknown through lack of skill in arguing from the available evidence or unknown through lack of evidence? He suggests that some sets of probabilities can be placed in ordered series, and it follows that of any pair one may be nearer to certainty than another.

He then suggests the following rules for those probabilities that can be set in an ordered series:

1 Every probability lies on a path between impossibility and certainty; it is always true to say of a degree of probability, which is not identical either with impossibility or certainty, that it lies between them. Thus certainty, impossibility and any other degree of probability form an ordered series.

2 A path or series, composed of degrees of probability, is not necessarily compact. It is not necessarily true that any pair of probabilities in the same series have a probability between them.

3 The same degree of probability can lie on more than one path, i.e., it can belong to more than one series. 
4 If $\mathrm{ABC}$ forms an ordered series, $\mathrm{B}$ lying between $\mathrm{A}$ and $\mathrm{C}$, and $\mathrm{BCD}$ forms an ordered series... then $\mathrm{ABCD}$ forms an ordered series.

In these circumstances he is taking an objective view of probability, but in some of the four views set out previously, probabilities cannot be accurately identified, a position that is very similar to Knight's (1921) concept of uncertainty.

\subsection{A compromise, Frank Knight: risk and uncertainty}

Indeed, Frank Knight (1921) spanned both views. He suggested that there are two fundamentally different ways of arriving at the probability judgment of the form that a given numerical proportion of X's are also Y's. The first method is by a priori calculation, and is applicable to and used in games of chance. This is also the type of case usually assumed in logical and mathematical treatments of probability. It must be strongly contrasted with the very different type of problem in which calculation is impossible and the result is reached by the empirical method of applying statistics to actual instances. As an illustration of the first type of probability we may take throwing a perfect die. If the die is really perfect and known to be so, it would be merely ridiculous to undertake to throw it a few hundred thousand times to ascertain the probability of its resting on one face or another. This is an example of what might be termed the objective view of probability.

At the same time, Knight also suggested that:

"On the other hand, consider the case already mentioned, the chance that a building will burn. It would be as ridiculous to suggest calculating from a priori principles the proportion of buildings to be accidentally destroyed by fire in a given region and time as it would to take statistics of the throws of dice".

This meant that for all practical purposes, this type of scientific probability was not met in business decisions.

\footnotetext{
"The import of this distinction for present purposes is that the first, mathematical or a priori, type of probability is practically never met with in business, while the second is extremely common. It is difficult to think of a business 'hazard' with regard to which it is in any degree possible to calculate in advance the proportion of distribution among the different possible outcomes. This must be dealt with, if at all, by tabulating the results of experience".
}

Knight suggested a simple scheme for separating three different types of probability situation:

1 A priori probability: absolutely homogeneous classification of instances completely identical except for really indeterminate factors. This judgment of probability is on the same logical plane as the propositions of mathematics (which also may be viewed, and are viewed by the writer, as 'ultimately' inductions from experience).

2 Statistical probability: empirical evaluation of the frequency of association between predicates, not analysable into varying combinations of equally probable alternatives. It must be emphasised that any high degree of confidence that the proportions found in the past will hold in the future is still based on an a priori judgment of indeterminateness. Two complications are to be kept separate: first, the impossibility 
of eliminating all factors not really indeterminate; and, second, the impossibility of enumerating the equally probable alternatives involved and determining their mode of combination so as to evaluate the probability by a priori calculation. The main distinguishing characteristic of this type is that it rests on an empirical classification of instances.

3 Estimates: the distinction here is that there is no valid basis of any kind for classifying instances. This form of probability is involved in the greatest logical difficulties of all, and no very satisfactory discussion of it can be given, but its distinction from the other types must be emphasised and some of its complicated relations indicated.

The third type is the type encountered in business decisions and is synonymous with his famous definition of uncertainty. Knight defined the first two types of probability as risk and the third as uncertainty. "To preserve the distinction which has been drawn ... between the measurable uncertainty and an unmeasurable one we may use the term 'risk' to designate the former and the term 'uncertainty' for the latter."

\subsection{The subjective view point Ramsey}

Ramsey (1926) took issue with Keyne's view. He differentiated between the type of probability used in physics and that in economic decision-making. He suggested a difference between:

"The kind of probability whose logarithm is the entropy - is really a ratio between the numbers, of two classes, or the limit of such a ratio. I do not myself believe this, but I am willing for the present to concede to the frequency theory that probability as used in modern science is really the same as frequency."

He criticises Keynes as follows:

"When it is said that the degree of the probability relation is the same as the degree of belief which it justifies, it seems to be presupposed that both probability relations, on the one hand, and degrees of belief on the other can be naturally expressed in terms of numbers, and then that the number expressing or measuring the probability relation is the same as that expressing the appropriate degree of belief. But if, as Mr. Keynes holds, these things are not always expressible by numbers, then we cannot give his statement that the degree of the one is the same as the degree of the other such a simple interpretation, but must suppose him to mean only that there is a one-one correspondence between probability relations and the degrees of belief which they justify."

Ramsey appeals to Hume as the foundation for his argument;

"Among the habits of the human mind a position of peculiar importance is occupied by induction. Since, the time of Hume a great deal has been written about the justification for inductive inference. Hume showed that it could not be reduced to deductive inference or justified by formal logic. So far as it goes his demonstration seems to me final; and the suggestion of Mr. Keynes that it can be got round by regarding induction as a form of probable inference cannot in my view be maintained. But to suppose that the situation which results from this is a scandal to philosophy is, I think, a mistake." 


\section{Modern finance and risk}

\subsection{Markowitz portfolio selection}

Harry Markowitz (1999) in a paper on the early history of portfolio theory mentions that in the Merchant of Venice, one of Shakespeare's characters in the play; the merchant Antonio says:

"My ventures are not in one bottom trusted,

Nor to one place; nor is my whole estate

Upon the fortune of this present year;

Therefore, my merchandise makes me not sad."

- Act 1 , Scene 1

He comments that not only did Shakespeare know about diversification but also understood covariance in an intuitive sense. Markowitz suggests that

"A portfolio analysis starts with information concerning individual securities. It ends with conclusions concerning portfolios as a whole. The purpose of the analysis is to find portfolios which best meet the objectives of investors".

"A second salient feature of security investment is the correlation among security returns. Like most economic quantities, the returns on securities tend to move up and down together. This correlation is not perfect: individual securities and entire industries have at times moved against the general flow of prosperity. On the whole, however, economic good and ill tend to spread, causing periods of generally high or generally low economic activity."

He draws on a line of thought from Bernoulli and Ramsey:

"Probability belief about the future is not necessarily a true, objective probability. Nevertheless, certain arithmetic relationships among past averages are exactly the same as corresponding relationships between random variables. The latter, in turn, are the same as relationships among probability beliefs. Thus a discussion of one of our topics can frequently serve as a discussion of all three".

"Returns on securities are uncertain events rather than random variables subject to known probabilities. This implies only that the expected returns, variances of returns, and covariances of return referred to in this chapter should be interpreted as based on probability beliefs rather than on objective probabilities".

"Suppose a rational man chooses a portfolio solely on the basis of its mean and variance. If two portfolios have the same mean and variance, they are considered equally good. Since the value of variance can be derived from the values of mean and $\operatorname{expt}\left(R^{2}\right)$ this Rational man can also be said to act on the basis of mean and $\operatorname{expt}\left(R^{2}\right)$. If two portfolio have the same $\operatorname{expt}(R)$ and $\operatorname{expt}\left(R^{2}\right)$, they have the same $\operatorname{var}(R)$ and, by assumption, must be considered equally good".

He considers rational choice when objective probabilities are not known for some or all contingencies. He links his discussion to the work of Ramsey and Savage. Individuals will act in the face of uncertainty as if they attached 'personal probabilities' to each contingency. They will proceed by maximising expected utility, using personal probabilities when objective probabilities are not known. 


\title{
Markowitz cautions that
}

\begin{abstract}
"Uncertainty cannot be dismissed so easily in the analysis of optimizing investor behaviour. An investor who knew future returns with certainty would invest in only one security, namely the one with the highest future return".
\end{abstract}

Investors would just choose the security with the highest return in they were not uncertain. They would not bother to diversify. Yet diversification is a common practice, and Markowitz suggests it is driven by a desire to reduce uncertainty. He adds that he will analyse decision making under these conditions as if investors faced known probability distributions, but adds: "Of course, none of us know probability distributions of security returns."

Markowitz (1999) points out that there were several antecedents to his development of portfolio theory and pointers to the tools applied. The ideas behind efficient diversification came from John Burr Williams' (1938) The Theory of Investment Value. Williams suggested that the expected present value of future dividends drives the value of a stock but a treatment of risk and diversification was lacking. Markowitz had the insight that diversification would reduce risk but would not eliminate it. Rubinstein (2002) suggests that this marked a tremendous leap forward. He continues that the important component of risk was identified as being the risk that a security contributes to a portfolio, not its total variance. This is driven by its covariance of returns with those of other securities.

Variance had been suggested as a measure of economic risk by Irving Fisher (1906) in The Nature of Income and Capital. Furthermore, Marschak (1938) had suggested using covariance matrices as an approximation for utility of consumption of commodities and Marschak was one of Markowitz's supervisors at the University of Chicago.

Markowitz notes that Roy (1952) suggested a portfolio selection model at the same time that he developed his approach. He developed an efficient set in a similar fashion but advised choosing a single portfolio on this set that maximises $\left(\mathrm{u}_{\mathrm{p}}-d\right) / \sigma_{\mathrm{p}}^{2}$ where $d$ is a disaster level return the investors wishes to avoid falling below. He suggests that Roy does not receive full credit for this.

The portfolio expected return is calculated as:

$$
E\left(R_{p}\right)=\sum_{i} w_{i} E\left(R_{i}\right)
$$

where $R_{i}$ is return and $w_{i}$ is the weighting of asset $i$.

And portfolio variance can be written as:

$$
\sigma_{p}^{2}=\sum_{i} w_{i}^{2} \sigma_{i}^{2}+\sum_{i} \sum_{j} w_{i} w_{j} \sigma_{i} \sigma_{j} \rho_{i j}
$$

where $i \neq j$. Alternatively the expression can be written as:

$$
\sigma_{p}^{2}=\sum_{i} \sum_{j} w_{i} w_{j} \sigma_{i} \sigma_{j} \rho_{i j}
$$

Markowitz (1959) in his book on portfolio theory extended his earlier work, and amongst other things, outlined the diagonal model in a footnote; an approach later extended by Sharpe. Markowitz (1999) suggests that the subsequent development of the capital asset pricing model owed a great deal to Tobin (1958). His famous separation theorem showed 
that "the proportionate composition of the non-cash assets is independent of their aggregate share of the investment balance", a direct parallel to the efficiency of the market portfolio in derivations of the CAPM. However, the primary focus of Tobin's analysis was to provide and improved theory for the holding of cash.

In contrast to Sharpe (1964) Tobin assumed that one can lend at the risk free rate but not borrow. Sharpe's more sweeping assumption that all can borrow or lend at the risk free rate together with the other assumptions about homogeneity of expectations etc. leads to the ubiquity of the capital market line when describing the efficient set. Markowitz (1999) points out that Tobin's assumptions were more cautious whereas, Sharpe's together with Lintner (1965) and Mossin (1966) lead directly on to the capital asset pricing model which was to revolutionise financial economics.

Markowitz's approach was a normative prescriptive one. He was interested in developing decision rules that could be applied by rational investors. He spent a great deal of time developing numerical algorithms and programming techniques. He was quite agnostic and practical in his recommendation of risk metrics. He did not explicitly make assumptions about the nature of probability density functions of returns. The adopted methods were very much a matter of convenience. However, Levy and Markowitz (1979) demonstrate that mean/variance analysis can be a good approximation for expected utility maximisation for quite a broad range of utility functions and empirical distributions.

Fama and Miller (1972) in their treatment of the analysis of portfolio decision making under conditions of risk suggest that mean/variance analysis as a decision criteria is legitimate when the distributions of returns on portfolios are normal, because normal distributions are defined by their first two moments.

Thus, mean/variance analysis came to occupy centre stage in financial economics. Meanwhile the development of the Black/Scholes option pricing model in 1973, built on the assumption that security prices are lognormally distributed or that returns are normally distributed. Their work, together with that of Merton (1973) is an approach yielding a pricing solution based on option replication strategies via dynamic trading. The 'risk neutral' property involved a continuously hedged portfolio of appropriate positions in the option and the underlying instrument. This permits the application of the risk free discount rate to evaluate the hedge portfolio but the hedge ratio would not be apparent without the prior assumption about the probability density function pertaining to the underlying asset. These insights lead to the 1997 Nobel Prize in economics and to a focus on risk measurement as input to the option pricing model. This leads directly to an explosion of interest in the financial econometrics literature.

\section{Risk modelling in financial econometrics}

\subsection{ARCH and GARCH models}

Robert Engle was one of the first to explore the modelling of volatility and was awarded the joint Nobel Economics Prize in 2003 for his work on ARCH modelling. He noted in his Nobel address that

\footnotetext{
"Optimal behavior takes risks that are worthwhile. This is the central paradigm of finance; we must take risks to achieve rewards but not all risks are equally rewarded. Both the risks and the rewards are in the future, so it is the expectation of loss that is balanced against the expectation of reward."
} 
In this speech he drew a direct connection between, his work, the previously discussed work on portfolio theory and the CAPM, and the development of option pricing models.

To use option pricing models in practice an estimate of the standard deviation, the square root of the variance; or volatility is required. A straightforward approach is to use the historical volatility of the returns on the underlying instrument, but how long a sample period should be used? Too long an interval yields an average volatility that is out of date; too short an interval produces a noisy estimate. Even then, ideally a forecast for the period in question is required. Further, empirical 'facts' about observed volatilities are that they tend to be clustered, high volatility with high subsequent volatility, and low with low. In 1982, when engaged in modelling inflation, Engle developed the autoregressive conditional heteroskedasticity or ARCH model. Engle provided the following explanation in his Nobel address:
"The ARCH model described the forecast variance in terms of current observables. Instead of using short or long sample standard deviations, the ARCH model proposed taking weighted averages of past squared forecast errors, a type of weighted variance. These weights could give more influence to recent information and less to the distant past. Clearly the ARCH model was a simple generalisation of the sample variance. The big advance was that the weights could be estimated from historical data even though the true volatility was never observed."

The forecasts can be calculated every day or every period and then evaluated. The particular set of weights can be identifies that make the forecasts closest to the variance of the next return by applying a procedure, based on maximum likelihood. Once this dynamic model of time varying volatility has been estimated it can be used to measure the volatility at any time and for forecasting purposes. Once the model had been developed, it potential applications in finance subsequently became apparent, given the central roles of risk and return and the availability of daily security prices, subsequently followed by real time, high frequency trading data.

In 1986, Bollerslev formulated the generalised autoregressive conditional heteroskedasticity $(\mathrm{GARCH})$. This generalises the autoregressive ARCH model to an autoregressive moving average model. The weights loaded on past squared residuals are assumed to reduce in a geometric fashion at a rate estimate from the data set. The GARCH forecast variance is made up of three components in the case of the standard GARCH(1,1) model, which uses one lag of past forecasts and past error sizes. One component is the intercept which is an average of the long run variance. The second is the forecast for the previous period and third is the size of the previous error.

The conditional mean return can be specified as:

$$
m_{t}=E_{t-1}\left[r_{t}\right]
$$

the conditional variance as:

$$
h_{t}=E_{t-1}\left[r_{t}-m_{t}\right]^{2}
$$

If we let $E_{t-1}[u]$ be the expectation of some variable $u$, given the information set available at time $t-1$. This might be referred to as $E\left[u \mid Z_{t-1}\right]$. This suggests that $R_{t}$ is generated by the following process: 


$$
R_{t}=m_{t}+\sqrt{h_{t} e_{t}}
$$

where the specification of conditional variance in a $\operatorname{GARCH}(p, q)$ model is:

$$
\begin{aligned}
& \varepsilon_{t}=h_{t}^{1 / 2} u_{t} \\
& h_{t}=\omega+\sum_{i=1}^{p} \alpha_{i} \varepsilon_{t-1}^{2}+\sum_{i=1}^{q} \beta_{i} h_{t-1}
\end{aligned}
$$

Usual requirements are that $\omega>0, \alpha$ and $\beta \geq 0$. These are sufficient conditions for the conditional variance to be positive. The conditional variance depends on the average volatility, constant value $\omega$, the error/reaction coefficient $\alpha$ and the lag/persistence coefficient $\beta$. The ARCH term is $\varepsilon_{t-1}^{2}$ is the which represents news about volatility from previous periods and the GARCH term, which is the last period's forecast variance $h_{t-1}$. Both parameters ( $\alpha$ and $\beta$ ) are sensitive to the historic data used to estimate the model. The size of the parameters $\alpha$ and $\beta$ determine the short run dynamics of the volatility. The closer the GARCH lag coefficient $\beta$ is to unity the greater the persistence of shocks to the conditional variance. A large ARCH error coefficient $\alpha$ causes volatility to react to market movements. The sum of the two components must be less than unity if the process is to be stationary. Typically a 'vanilla' GARCH $(1,1)$ model with one lag is most appropriate in many applications.

There are a wide variety of GARCH models. Hentschel (1995) provides a family of nested symmetric and asymmetric models. Bauwens et al. (2006) provide a survey of multivariate GARCH models, and Bollerslev (2008), provides a glossary to $\mathrm{ARCH}(\mathrm{GARCH})$. A shall mention just a few variants to provide a flavour of the literature.

Engle and Bollerslev (1986) suggested a nonlinear GARCH (NGARCH) model, which involves a reduced response to extreme news if $\alpha_{2}<2$.

$$
h_{t}=\omega+\alpha_{1}\left|\varepsilon_{t-1}\right|^{\alpha_{2}}+\beta_{1} h_{t-1}
$$

For the above two models positive and negative past values have a symmetric effect on the conditional variance. Many financial series however are strongly asymmetric. Negative equity returns are followed by larger increases in volatility than equally large positive returns.

Based on the leverage effects, Nelson (1991) [following the work of Black (1976), Christie (1982), and French et al. (1987)] proposed the exponential GARCH (EGARCH) model, which allows for asymmetry in responses to shocks to returns. Downward movements in asset prices often lead to greater increases in volatility than upward movements.

$$
\begin{aligned}
\log \left(h_{t}\right) & =\omega+\beta_{1} \log \left(h_{t-1}\right)+\alpha_{1}\left[\left|\varepsilon_{t-1}\right| /\left(h_{t-1}\right)^{1 / 2}-(2 / \pi)^{1 / 2}\right] \\
& +\alpha_{2}\left[\varepsilon_{t-1} /\left(h_{t-1}\right)^{1 / 2}\right]
\end{aligned}
$$

This model avoids non-negativity constraints on the parameters of the model by applying logs. The parameter $\alpha_{2}$ can generate the leverage effect because this permits the sign of yesterday's shock to be in the model. 
Yet another specification for the conditional volatility process is the GJR model proposed by Glosten et al. (1993). This introduces asymmetric effects by including a dummy variable as shown in the equation below:

$$
h_{t}=\omega+\beta_{1} h_{t-1}+\alpha_{1} \varepsilon_{t-1}^{2}+\alpha_{2} S_{t-1}^{-} \varepsilon_{t-1}^{2}
$$

The indicative dummy $S_{t-1}^{-}$takes the value of 1 if the value of the $\varepsilon_{t-1}<0$ and 0 otherwise. Note, that while the impact of a piece of positive news is estimated by $\alpha_{1}$ alone, the impact of negative news is given by the sum of $\alpha_{1}$ and $\alpha_{2}$. Other variations on GARCH type models, which capture the asymmetric response of volatility to news, are presented in below.

The Asymmetric GARCH model (AGARCH) by Engle (1990):

$$
h_{t}=\omega+\beta_{1} h_{t-1}+\alpha_{1}\left(\varepsilon_{t-1}+\alpha_{2}\right)^{2}
$$

The models above allow several types of asymmetry in the impact of news on volatility. To capture the qualitative differences between alternative volatility models Engle and $\mathrm{Ng}$ (1993) define the news impact curve which characterises the impact of past return shocks $\varepsilon_{t-1}$ on the return volatility $h_{t}$ implicit in volatility models. The differences between the models presented above can be compared by contrasting their news impact curves. The news impact curve of EGARCH and GJR models has a minimum at $\varepsilon_{t-1}=0$, but has asymmetric positive and negative sides. The AGARCH model is asymmetric as well; however, it is centred at $\varepsilon_{t-1}=-\alpha_{2}$. This brief description only scratches the surface of the vast family of GARCH models. A comprehensive review of the extensive literature up to the early 1990s (and it has expanded greatly since then), is provided by Bollerslev et al. (1992).

\subsection{Stochastic volatility models}

Stochastic volatility models are based on continuous time processes and therefore both the asset price and volatility follow a diffusion process. The general equation, (see Asai and McAleer, 2005), for the mean of a time varying volatility model can be specified as;

$$
y_{t}=\mu_{t}+e_{t}, e_{t}=h_{t}^{1 / 2} \varepsilon_{t}, \varepsilon_{t} \sim N I D(0,1), t=1, \ldots . . T,
$$

where $y_{t}$ denotes the return series of interest and $\mu_{t}$ its expectation. In the case of stochastic volatility models the mean is often assumed to be zero and modelled before the estimation of the volatility process. The disturbance term $\varepsilon_{t}$ is assumed to be i.i.d. normal with zero mean and unit variance.

A common specification for the variance equation is:

$$
\sigma_{t}^{2}=\sigma^{* 2} \exp \left(h_{t}\right)
$$

Thus it is defined as the multiple of a positive scaling factor $\sigma^{* 2}$ and the exponential of the stochastic process $h_{t}$. In the standard SV model $h_{t}$ is specified as an autoregressive order one process. This makes it capable of capturing volatility clustering whereby; 


$$
h_{t}=\phi h_{t-1}+\sigma_{n} \eta_{t}, \eta_{t} \sim N I D(0,1)
$$

In the above expression the degree of volatility persistence is captured by the value of the coefficient $\varphi$ which is restricted to having a positive value smaller than 1 to ensure that the process is a stationary and non-oscillating log volatility process. A discussion of stochastic volatility models is provided in Asai and McAleer (2005) and McAleer (2005). These models can be augmented to include leverage effects. Estimation of these models can be complex when the parameters of the logarithm of a squared normal random variable is required. Techniques such as Bayesian Markov chain Monte Carlo (MCMC) techniques have been recently applied. Given the estimation difficulties attention has recently switched to realised volatility models.

\subsection{Realised volatility models}

Andersen et al. (2003) provide a general framework for integration of high-frequency intraday data into the measurement, modelling, and forecasting of daily and lower frequency return volatilities and return distributions. They build on a framework provided by Barndorff-Neilsen and Shephard (2002). They point out that most procedures for modelling and forecasting financial asset return volatilities, correlations, and distributions rely on potentially restrictive and complicated parametric multivariate ARCH or stochastic volatility models. The advantage of applying realised volatility metrics constructed from high-frequency intraday returns, are that they permit the use of traditional time-series methods for modelling and forecasting. McAleer and Medeiros (2003) provide a review of realised volatility models.

Allen et al. (2008) use estimates of realised volatility to build an auto-regressive fractionally-integrated model (ARFIMA) of the behaviour of realised volatility. The model is augmented to incorporate calendar effects, leverage effects and the time-varying volatility of volatility. The details will not be pursued here, but the next two figures are taken from this paper. One problem frequently encountered, is that standard GARCH models do not capture the explosive behaviour in the tails of return distributions. If we set a day as a unit of measurement, as usual, and sample the continuously compounded intraday returns of day $t$ at frequency $M$,

$$
r_{j t}=p_{t-1+j / m}-p_{t-1+(j-1) / M}
$$

The realised quarticity over day $\mathrm{t}$ can be defined as:

$$
R Q_{t}=\frac{M}{3} \sum_{j=1}^{M} r_{t, k}^{4} \rightarrow \int_{0}^{t} \sigma(s)^{4} d s
$$

A metric developed from this is used to sample realised quarticity for S\&P 500 Index data, obtained from SIRCA using high frequency intraday data obtained from SIRCA's Taqtic Reuters database for 2 January 1996 to 26 March 2007. 
Figure 2 S\&P $500 \sqrt{R Q}$ January 1996 - March 2007 (see online version for colours)

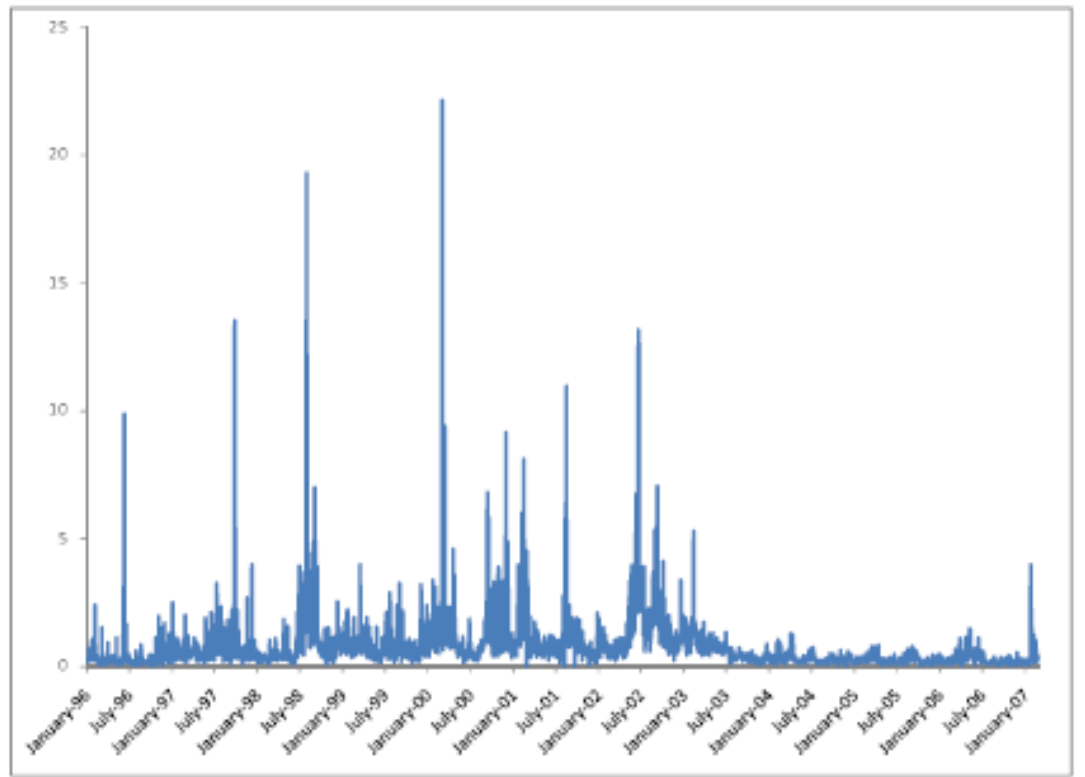

Figure 3 Why shocks to volatility matter. The difference between conditional forecasts from a GARCH $(1,1)$ model and direct estimates from high frequency data, S\&P 500 Index data, January 1996 - March 2007

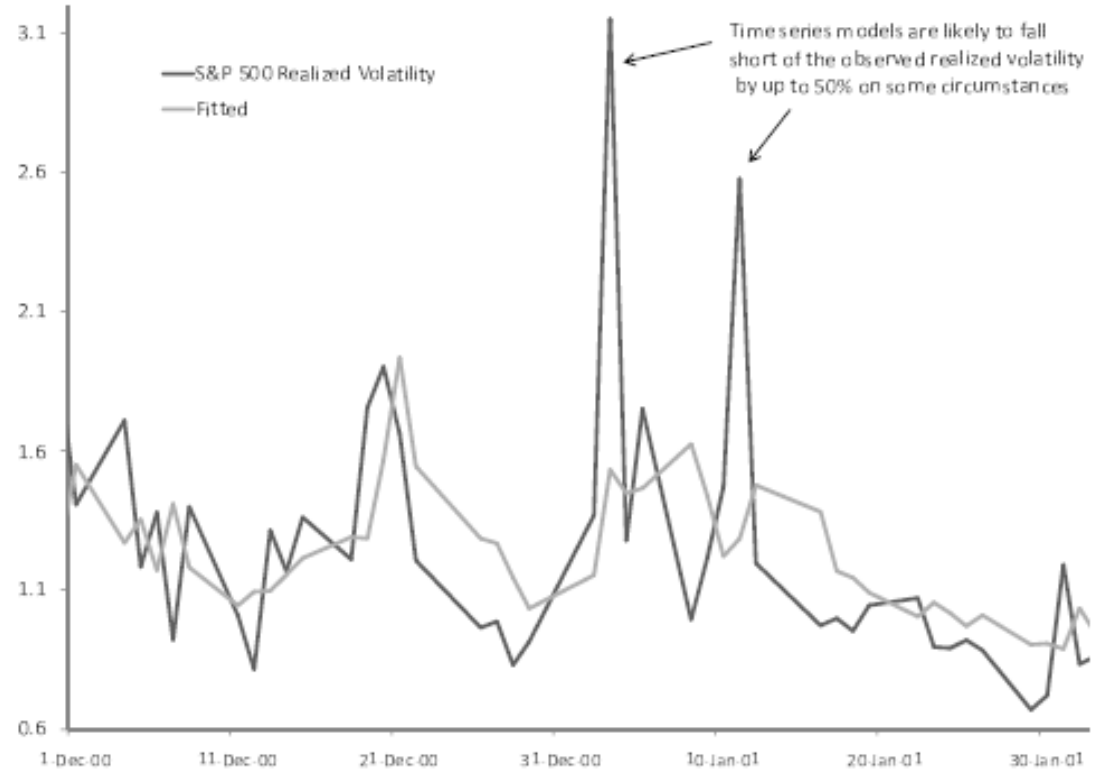


Figure 4 Persistence in the Volatility of volatility S\&P500 $\sqrt{R Q}$ : autocorrelation (see online version for colours)

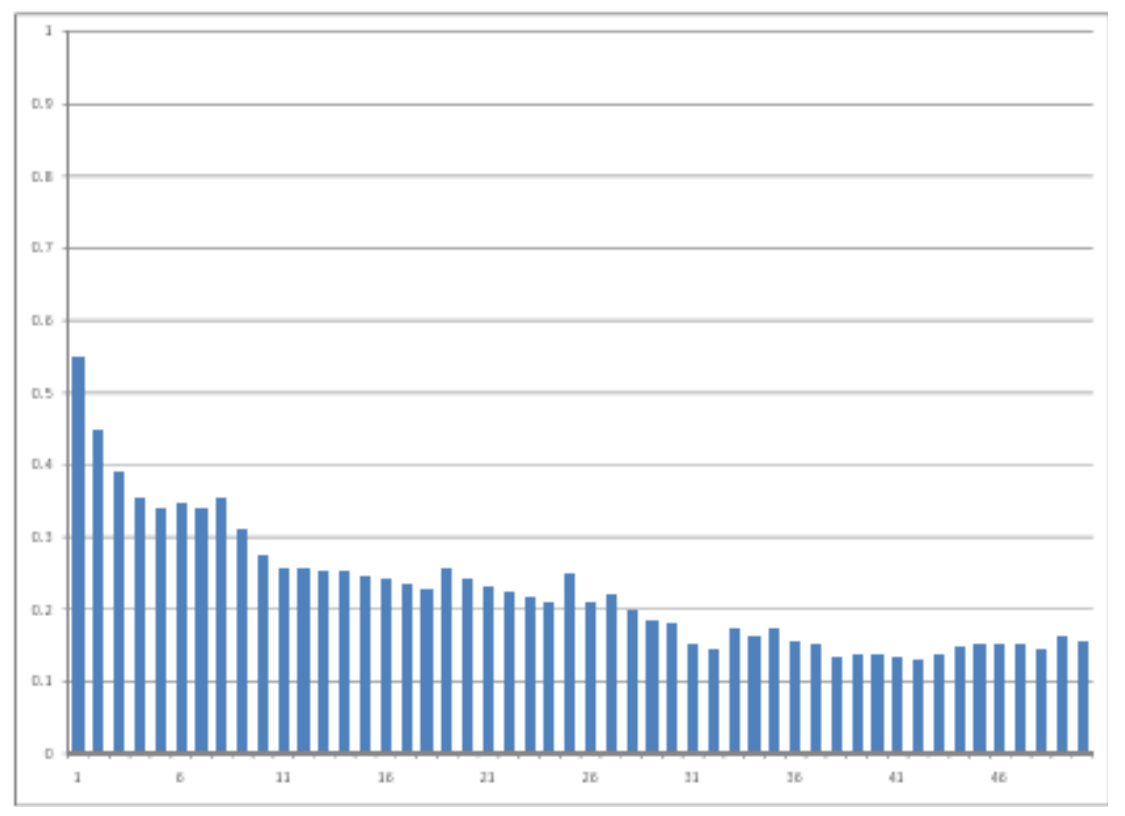

We estimated the following HAR model from our full sample.

$$
\begin{aligned}
\sqrt{R Q_{t}} & =\underset{(0.029)}{0.131}+\frac{0.275}{(0.022)} \sqrt{R Q_{t-1}}+\frac{0.085}{(0.024)} \sqrt{R Q_{t-2}} \\
& +\underset{(0.047)}{0.276} \sqrt{R Q_{t-i, 5}}+\frac{0.232}{(0.037)} \sqrt{R Q_{t-i, 22}}+\widehat{u_{t}}
\end{aligned}
$$

$$
R^{2}=0.148, B I C=2.900
$$

We then augmented our model with a number of different specifications to capture leverage effects in the behaviour of the volatility of volatility. Our HAR augmented model appears to work best in out of sample forecasting tests. The behaviour of the volatility of volatility is shown below in Figure 5. It can be seen in this figure that returns below about negative one percent generate an explosive regime in the volatility of volatility. 
Figure 5 S\&P500 Estimated volatility of volatility
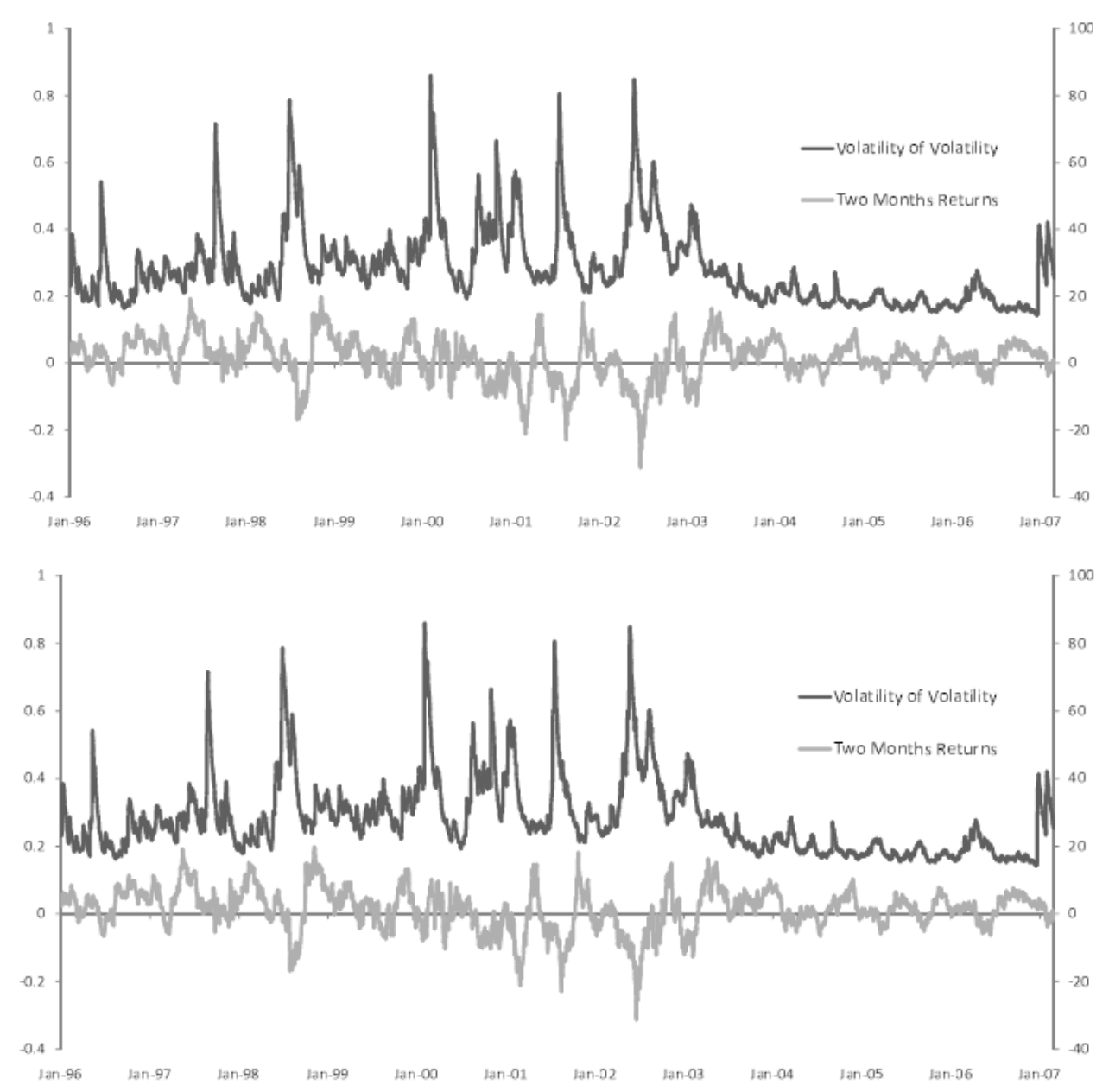

\subsection{Implied volatility}

\subsubsection{Black-Scholes OPM}

Another way of deriving measures of volatility is via an option pricing model and its implied standard deviation (ISD). This started with the first closed-form option pricing model derived by Black and Scholes (1973) and has been expanded to various generalisations. If $f$ denotes the option pricing model and $\mathrm{c}$ is the price of the option; then

$$
c=f(S, X, \sigma, R, T)
$$


where

$S=$ price of the underlying security

$X=$ the exercise price

$\sigma=$ volatility (standard deviation of the return on the underlying security)

$R=$ risk-free interest rate

$T=$ time until option expiry.

The option is priced by the five variables on the RHS of the above expression. The one that is most problematic and difficult to measure is the volatility. The price is quite sensitive to the volatility (the option Vega measures this sensitivity). In their original development of the option pricing model Black and Scholes assumed a continuous lognormal distribution as the probability density function of the underlying distribution of returns on the security against which the option is priced. Another way of using the model is to input the observed option price, and the other four readily observable variables; security price, risk free rate, exercise price, time to maturity and impute the implied volatility (ISD). Latane and Rendleman (1976) were amongst the first to use this approach. There are a number of factors that can muddy the estimation; non-sychronised prices of the underlying and the option, thin markets, etc, but in recent years with the growth in derivatives markets trading and the spread in the availability of real time trading data this is not such an issue. The assumption in the Black-Scholes model is one of a constant underlying volatility. A great deal of work has been done on 'volatility smiles'; the recurring phenomena that deep in or out of the money options typically have higher ISDs than at the money options on the same underlying. The model predicts that they should be the same.

\subsubsection{The VIX index}

A common measure of volatility is the VIX index. The VIX is the Chicago Board Options Exchange Volatility Index which measures the implied volatility of S\&P 500 index options. A high value represents a more volatile market with more expensive options, given that option prices increase with greater volatility, and the VIX is a made up of a weighted blend of prices for a range of options on the S\&P 500 Index. The VIX is often called the fear index, as it represents an estimate of the market's expectation of volatility over the next 30 day period. The VIX has more than 20 years of historical prices available which can be used to assess option volatility in a variety of market conditions. The price history for the original CBOE Volatility Index (Ticker - 'VXO') based on OEX options is available from 1986 to the present. CBOE has created a similar historical record for the new VIX dating back to 1990 so that investors can compare the new VIX with VXO.

Whaley (2009) notes that the S\&P 500 Index option market has become dominated by hedgers who buy index puts to insure against potential market drops. On 22 September 2003, the CBOE changed the calculation of the VIX to account for the switch in volume from the OEX to SPX (from the S\&P 100 index to the 500 index), and to the heavy use of at the money and out of the money puts for portfolio insurance purposes. 
Figure 6 The VIX Index and S\&P 500 Index. Friday closing levels during the period 3 January 1986 to 31 October 2008 (see online version for colours)

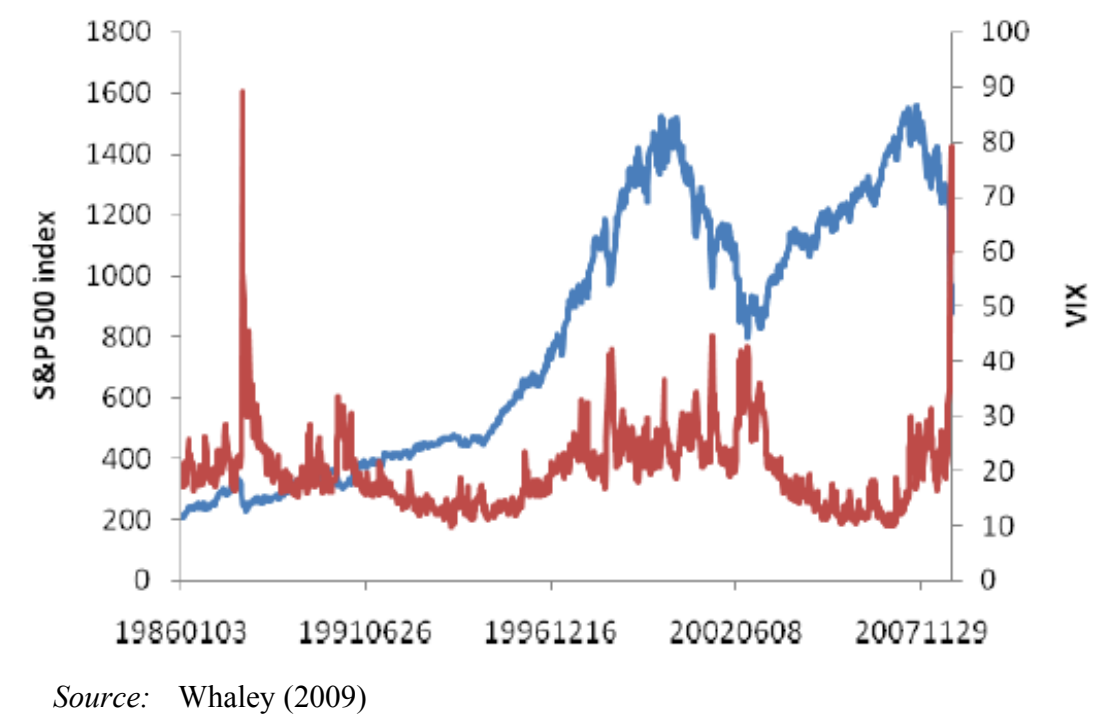

Figure 6 shows the week-ending levels of the S\&P 500 index and the VIX from the beginning of January 1986 through to 31 October 2008. The VIX stood at a record high after the 19 October 1987 market crash when it exceeded a level of 100 . The spike at the end of the graph shows the impact of the onset of the Global Financial Crisis. The VIX is a predictor or forward looking index of the expected return volatility of the S\&P 500 index for the next 30 days.

\subsection{Value at risk}

Value at risk $(\mathrm{VaR})$ is a procedure designed to forecast the maximum expected loss over a given period at an expected confidence level. The use of $\mathrm{VaR}$ has become all-pervasive in a relatively short period of time despite its conceptual and practical shortcomings. VaR received its first broad recommendation in the 1993 Group of Thirty Report. Subsequently its use and recognition have increased dramatically, particularly when the Basel Committee on Banking Supervision adopted the use of VaR models, contingent upon certain qualitative and quantitative standards. VaR has subsequently become one of the most important and widely used measures of risk. As a risk-management technique VaR describes the loss that can occur over a given period, at a given confidence level, due to exposure to market risk. The appealing simplicity of the VaR concept has lead to its adoption as a standard risk measure for financial entities involved in large scale trading operations, but also retail banks, insurance companies, institutional investors, and non-financial enterprises. Its use is encouraged by the Bank for International Settlements, the American Federal Reserve Bank and the Securities and Exchange Commission.

The groundbreaking Basel Capital Accord, originally signed by the Group of Ten (G10) countries in 1988, but since largely adopted by over 100 countries, requires authorised deposit-taking institutions (ADIs) to hold sufficient capital to provide a cushion against unexpected losses. VaR is a procedure designed to forecast the maximum expected loss over a target horizon, given a (statistical) confidence limit. Initially, the 
Basel Accord stipulated a standardised approach which all institutions were required to adopt in calculating their VaR thresholds. This approach suffered from several deficiencies, the most notable of which were its conservatism (or lost opportunities) and its failure to reward institutions with superior risk management expertise.

Following much industry criticism, the Basel Accord was amended in April 1995 to allow institutions to use internal models to determine their VaR and the required capital charges. However, institutions wishing to use their own models are required to have the internal models evaluated by the regulators using the back-testing procedure.

A description of the various methodologies for the modelling of VaR can be seen at http://www.gloriamundi.org/. The predominant approaches to calculating VaR rely on a linear approximation of the portfolio risks and assume a joint normal (or log-normal) distribution of the underlying market processes. There is a comprehensive survey of the concept by Duffie and Pan (1997), and discussions in Jorion (1996), and RiskMetrics ${ }^{\mathrm{TM}}$ (1996).

Despite its universal adoption and promotion by the regulatory authorities and its embrace by the financial services industry there are a number of theoretical and practical difficulties associated with the use of VaR as a risk metric. A standard procedure, in terms of the practical implementation of VaR metrics, if the portfolio of concern contains non-linear instruments such as options, is to make recourse to historical or Monte-Carlo simulation based tools.

Nevertheless, despite its popularity, VaR has certain undesirable mathematical properties; such as lack of sub-additivity and convexity; see the discussion in Arztner et al. (1997, 1999). In the case of the standard normal distribution VaR is proportional to the standard deviation and is coherent when based on this distribution but not in other circumstances. The VaR resulting from the combination of two portfolios can be greater than the sum of the risks of the individual portfolios. A further complication is associated with the fact that VaR is difficult to optimise when calculated from scenarios. It can be difficult to resolve as a function of a portfolio position and can exhibit multiple local extrema, which makes it problematic to determine the optimal mix of positions and the VaR of a particular mix.

An attractive alternative to VaR is CVaR - conditional-value-at-risk. Pflug (2000) proved that $\mathrm{CVaR}$ is a coherent risk measure with a number of desirable properties such as convexity and monotonicity w.r.t. stochastic dominance of order 1, amongst other desirable characteristics. Furthermore, VaR gives no indication on the extent of the losses that might be encountered beyond the threshold amount suggested by the measure. By contrast CVaR does quantify the losses that might be encountered in the tail of the distribution. This is because a portfolio's CVaR is the loss one expects to suffer, given that the loss is equal to or larger than its VaR.

VaR calculates maximum expected losses over a given time period at a given tolerance level. There are three methods of calculating VaR. The variance-covariance method estimates VaR on assumption of a normal distribution. The historical method groups historical losses in categories from best to worst and calculates VaR on the assumption of history repeating itself. The Monte Carlo method simulates multiple random scenarios.

CVaR is closely related to VaR. CVaR is equal or greater than VaR. It is the conditional expected loss under the condition it exceeds VaR. CVaR is also called mean excess loss, mean shortfall, or tail VaR. $\beta$-VaR is a value with probability $\beta$ the loss will not exceed $\beta$-VaR. CVaR is the mean value of the worst $(1-\beta)^{*} 100 \%$ losses. For 
instance, if we are measuring VaR at a $95 \%$ confidence level $(\beta=0.95)$, CVaR is the average of the 5\% worst losses. [Uryasev and Rockafellar, (1999), pp.1-2]. CVaR can be calculated using the actual 5\% worst losses (nonparametric). CVaR can also be calculated using a normal distribution (parametric) approach, as shown below:

$$
C V a R_{\alpha}=\frac{\exp \left(-\frac{q_{\alpha}^{2}}{2}\right)}{\alpha \sqrt{2 \pi}} \sigma
$$

where $q_{\alpha}$ is the tail $100_{\alpha}$ percentile of a standard normal distribution (e.g., 1.645 as obtained from standard distribution tables for $95 \%$ confidence).

Allen and Powell (2009) have compared changes in bank default risk in the USA and UK over time, including the current crisis period. A common approach used by banks to measure the probability of default among customers is the KMV/Merton structural model which measures distance to default. We use this same approach to measure the distance to default of the banks themselves. As a further measure of variation of Bank risk over time we use the VaR methodology to examine the banks' equity risk, as well as the increasingly popular $\mathrm{CVaR}$ methodology to measure their extreme equity risk. In addition, we incorporate $\mathrm{CVaR}$ techniques into structural modelling to measure extreme default risk. The study finds that US and UK banks are in an extremely precarious capital position based on market asset values, especially in the UK where the banks are more highly leveraged. We also find the existing credit ratings of Banks are much more favourable than default probabilities indicate they should be. Movements in market asset values are currently not factored into capital adequacy requirements, and based on our findings, recommendations are made for a revised capital adequacy framework. It is also possible to combine an option pricing model based approach and CVaR to work out implied distance to default.

\subsection{How well do these models forecast?}

Poon and Granger $(2003,2005)$ undertake an extensive review of the volatility forecasting literature. They reviewed 93 volatility studies and summarised the pairwise outcomes of studies that featured a direct comparison of the forecasting performance of different models. Their overall ranking suggested that implied standard deviations provided the best forecasts, followed by estimates of historical volatility, and GARCH with roughly equal performance. They also suggested that the number of studies using stochastic volatility is so small that it is not possible to make meaningful comparisons of performance. They comment that the success of implied volatility methods is not surprising because these methods tend to be based on larger and more timely information sets. They suggest a set of guidelines for forecasting volatility. The first considers the importance of considering the objectives of the forecasting exercise. No one model will fit all purposes and for example, forecasting the tail of a distribution might not be the same as forecasting implied volatility to price an option. High frequency data often produces accurate estimates of volatility but care must be taken of potential contamination from microstructure noise in very high frequency data. Historical standard deviations are model free but depend on how they are calculated, time intervalling, period, method of calculation, etc. Conditional volatility models based on ARCH, 
GARCH, stochastic volatility models, or option based implied volatility models are subject to model misspecification errors. Implied volatility from option pricing models is known to be subject to systematic bias. The forecasts appear to work much better in the short term than over longer horizons. For example the forecasting power for stock index volatility is $50-58 \%$ for horizons from one to 20 trading days.

\section{Risk models and the global financial crisis}

I commenced this review of approaches to modelling risk with a brief mention of David Hume's caution that the laws of cause and effect are based on customary observation. A view conditioned by the presumption that the world will remain the same. The financial world is subject to constant change and innovation and the human agents within it learn from their mistakes and revise their anticipations of anticipated outcomes on a continuing basis. It seems apparent that these revisions are likely to be subjective in the manner suggested by Ramsey rather than objective in the fashion suggested by Keynes.

The treatment and assessment of risk holds centre stage in finance yet the original development of portfolio theory by Markowitz was as a heuristic decision device rather an all prevailing metric for assessing risk. Mean variance analysis came to occupy centre stage in finance and the convenient presumption of multivariate normal distributions. The work on option pricing and in modelling volatility in financial econometrics has lead to an enormous advance in the techniques available for modelling and forecasting risk, plus an appreciation of the difficulties involved in modelling the tails of distributions.

However, none of these developments lead to an awareness or prediction of the Global Financial Crisis. The reviews have shown that the forecasts are predominantly short-term in nature. There are notable exceptions to this and Robert Shiller had been warning of the dangers of an over-heated US housing market well before the onset of the crisis in 2007. Figure 7 below shows S\&P data for lagged two year housing prices in the US, as cited by Gorton (2009).

Figure 7 Lagging two year house price appreciation (\%) S\&P Case-Shiller National US Index

The Subprime Panic

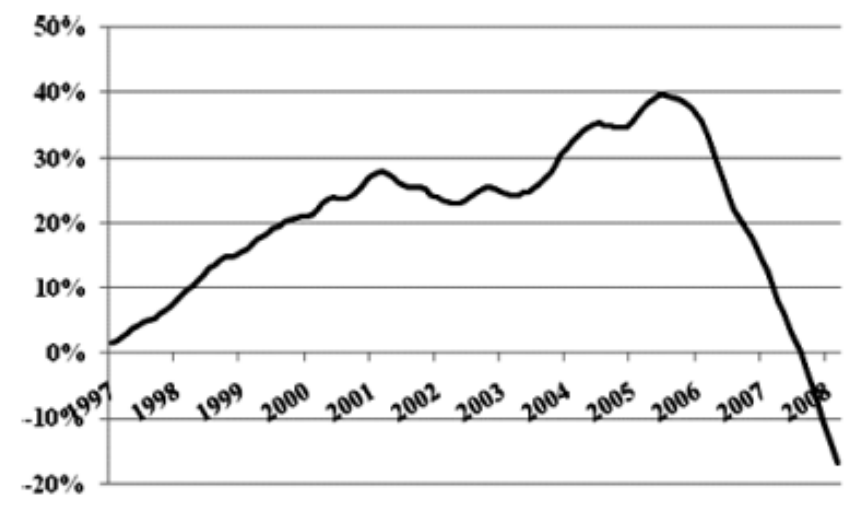

Source: Gorton (2009) 
Gorton asks what triggered the Panic of 2007 and suggests that house price declines and foreclosures do not explain the panic. He argues that the problem lies with asymmetric information. Dealer banks had the information about the subprime-related structures, and about the placement of the various bonds. But, there was no way to learn the consensus value of these bonds and structures. There was no mechanism for the revelation and aggregation of diverse information about the effects of the house price decline and the foreclosures.

Figure 8 Asset Backed Commercial Paper Outstanding in the USA

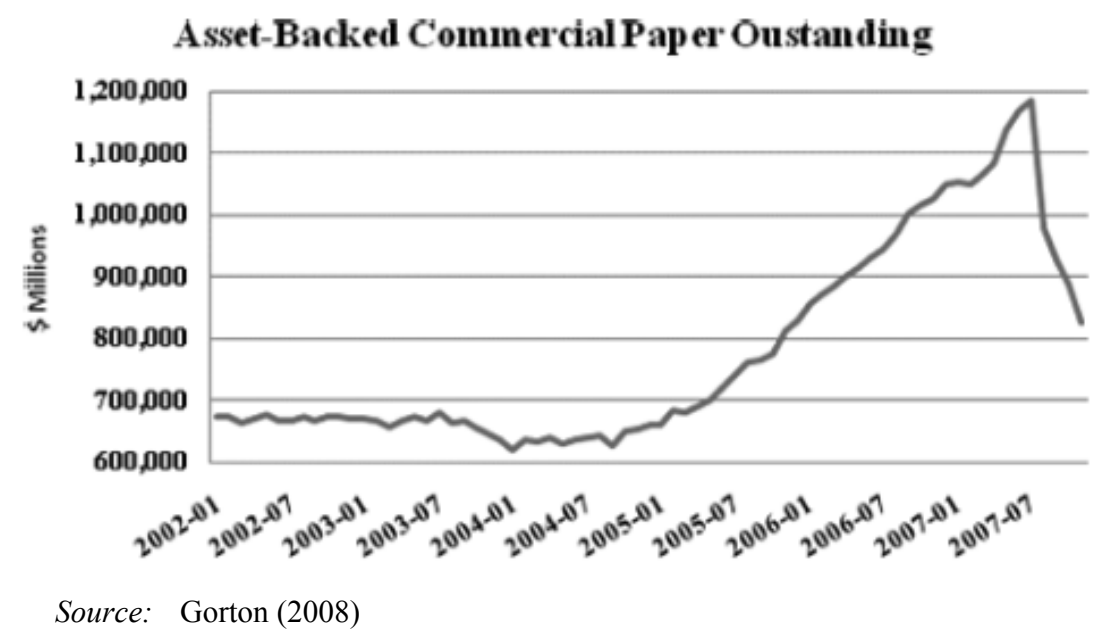

Once the problems emerged in the sub-prime market in 2007 the ramifications began to spread with difficulties at Freddie Mac and Bear Stearns in April and in June 2007. The reverberations continue around the globe with French bank BNP Paribas suspending three funds in August 2007. Central banks then begin to coordinate efforts to increase liquidity and the crisis begins to gather momentum. On 14 September 2007, the UK bank Northern Rock sought and received a liquidity support facility from the Bank of England, following problems in the credit markets and the first UK bank run for over a century. The bank was subsequently taken into state ownership.

By March 2008, Bear Stearns had been acquired by J.P. Morgan Chase at $\$ 2.00$ per share in a fire sale to avoid bankruptcy. On 7 September 2008 there was a Federal takeover of Fanny Mae and Freddy Mac. On 14 September, Merrill was sold to Bank of America and the following day Lehmann Bros. file for bankruptcy protection. Two days later the Federal Reserve lends support to American International Group AIG. Henry Paulson and Ben Bernanke then propose a $\$ 700$ million emergency bail-out fund for purchasing toxic assets. By October, the financial crisis spreads to Europe. England, China, Canada, Sweden, Switzerland and the European Central Bank cut rates in a coordinated effort to aid the world economy. Nine US banks participate in a Federal Government support program:

1 Bank of America

2 JPMorgan Chase

3 Wells Fargo 
4 Citigroup

5 Merrill Lynch

6 Goldman Sachs

7 Morgan Stanley

8 Bank of New York Mellon

9 State Street.

The crisis spread rapidly causing a global economic shock, and a number of European bank failures followed. Global stock markets declined and there were large reductions in the market values of equities and commodities. Financial institutions delevered to pay back obligations, credit spreads widened and a global liquidity crisis resulted as banks refused to lend to one another and to customers. This then transmitted a synchronised global negative shock to the global real economy and international trade decreased. I think it would be true to say that very few foresaw the scale and the scope of the global problem.

\section{Conclusions}

There has been a remarkable development and extension of the methods available to model risk in recent years. Some of the more notable developments have been reviewed in this paper. Most of the models are predicated on the assumption of 'business as usual'. They are quite a good for modelling the risk of an individual entity when external economic circumstances and behaviour remain the same. They are not adequate when economic behaviour changes, and the 'normal rules' do not apply, as has been the case with the recent drying up of liquidity and normal bank lending during the global financial crisis. In recent times we have faced uncertainty on a global scale in the manner defined by Frank Knight.

\section{References}

Allen, D.E, McAleer, M. and Scharth, M. (2008) Realised Volatility Uncertainty, School of Accounting Finance and Economics, Edith Cowan University, WP 0807.

Allen, D.E. and Powell, R. (2009) 'Bank default risk in the US and the UK', G.N. Gregoriou (Ed.): Chapter in Banking Crises, Chapman-Hall/Taylor and Francis London, UK.

Andersen, T., Bollerslev, T., Diebold, F.X. and P. Labys (2003) 'Modeling and forecasting realized volatility', Econometrica, Vol. 71, pp.529-626.

Artzner, P., Delbaen, F., Eber, J.M. and Heath, D. (1997) 'Thinking coherently', Risk, Vol. 10, pp.68-71.

Artzner, P., Delbaen, F., Eber, J.M., and Heath, D. (1999) 'Coherent measures of risk', Mathematical Finance, Vol. 9, pp.203-228.

Asai, M. and M. McAleer (2005) 'Asymmetry and leverage in stochastic volatility models: an exposition', in A. Zerger and R. Argent (Eds.): MODSIM 2005 International Congress on Modelling and Simulation, MSSANZ, Melbourne, Australia, December 2005, pp.2283-2287 (ISBN 097584002 9).

Barndorff-Nielsen, O.E. and Shephard, N. (2002) 'Econometric analysis of realised volatility and its use in estimating stochastic volatility models', Journal of the Royal Statistical Society B, Vol. 64, pp.253-280. 
Bauwens, L., Laurent, S. and Rombouts, J.V.K. (2006) 'Multvariate GARCH models: a survey', Journal of Applied Econometrics, Vol. 21, pp.79-109.

Bernouilli, D. (1954) 'Exposition on a new theory of risk', Econometrica, Vol. 22, No. 1, pp.23-36, translated from the original into English by Dr. Louise Sommer, The American University, Washington, D.C., from 'Specimen theoriae novae de mensura sortis', Commentarii, Academiae Scientiarum Imperialis Petropolitanae, Tomus V (Papers of the Imperial Academy of Sciences in Petersburg, Vol. 5), 1738, pp.175-192.

Black, F. (1976) 'Studies of stock price volatility changes', Proceedings of the 1976 Meetings of the American Statistical Association, Business and Economics Statistics Section, pp.177-181.

Black, F. and Scholes, M. (1973) 'The pricing of options and corporate liabilities', Journal of Political Economy, Vol. 81, No. 3, pp.637-654.

Bollerslev, T. (1986) 'Generalized autoregressive conditional heteroskedasticity', Journal of Econometrics, Vol. 31, pp.307-327.

Bollerslev, T. (2008) 'Glossary to ARCH (GARCH)', CREATES Research Paper 2008-49, Duke University.

Bollerslev, T., Chou, R.Y. and Kroner, K.F. (1992) 'ARCH modeling in finance: a review of the theory and empirical evidence', Journal of Econometrics, Vol. 52, pp.5-59.

Burr-Williams, J. (1938) The Theory of Investment Value, North Holland Publishing, Amsterdam.

Christie, A.A. (1982) 'The stochastic behaviour of common stock variances: value, leverage and interest rate effects', Journal of Financial Economics, Vol. 10, pp.407-432.

Duffie, D. and Pan, J. (1997) 'An overview of value at risk', Journal of Derivatives, No. 4, pp.7-49.

Engle, R.F. (1982) 'Autoregressive conditional heteroskedasticity with estimates of the variance of UK inflation', Econometrica, Vol. 50, pp.987-1008.

Engle, R.F. (1990) 'Discussion: stock market volatility and the crash of '87', Review of Financial Studies, Vol. 3, pp.103-106.

Engle, R.F. (2003) 'Nobel Prize address', available at http://nobelprize.org/nobel_prizes/economics/laureates/2003/engle-lecture.pdf.

Engle, R.F. and Bollerslev, T. (1986). Modeling the persistence of conditional variances. Econometric Review , 5, 1-50.

Engle, R.F. and Ng, V. (1993) 'Measuring and testing the impact of news on volatility', Journal of Finance, Vol. 48, pp.1749-1778.

Fama, E.F. and Miller, M.H. (1972) The Theory of Finance, Holt, Rinehart and Winston.

Fisher, I. (1906) The Nature of Capital and Income, Macmillan, London.

French, K.R., Schwert, G.W. and Stambaugh, R.F. (1987) 'Expected stock returns and volatility,' Journal of Financial Economics, Vol. 19, pp.3-30.

Glosten, L.R., Jagannathan, R. and Runkle, D. (1993) 'On the relation between the expected value and the volatility of the nominal excess return on stocks', Journal of Finance, Vol. 48, pp.1779-1801.

Gorton, G. (2009) “The subprime panic', European Financial Management, Vol. 25, No. 1, pp.10-46.

Granger, C.W.J. (1969) 'Investigating causal relations by econometric models and cross-spectral methods', Econometrica, Vol. 37, No. 3, pp.424-438.

Hentschel, L. (1995) 'All in the family Nesting symmetric and asymmetric GARCH models', Journal of Financial Economics, Vol. 39, No. 1, pp.71-104.

Holton, G.A. (2004) 'Defining risk', Financial Analysts Journal, pp.19-25.

Hume, D. (1739 and 1740) A Treatise of Human Nature, sourced from Project Gutenborg, available at http://www.gutenberg.org/etext/4705.

J.P. Morgan \& Reuters (1996) 'RiskMetrics Technical Document', available at www.riskmetrics.com/rmcovv.html. 
Jorion, P. (1996) Value at Risk: A New Benchmark for Measuring Derivative Risk, Irwin Professional Publishing.

Keynes, J.M. (1921) A Treatise on Probability, Macmillan and Co., London.

Knight, F.H. (1921) Risk Uncertainty and Profit, Hart, Schaffner \& Marx; Houghton Mifflin Co., Boston, MA.

Latane, H.A. and Rendleman, J.R. (1976) 'Standard deviations of stock price ratios implied in options on stock price index futures', Journal of Finance, Vol. 31, No. 2, pp.369-381.

Levy, H. and Markowitz, H. (1979) 'Approximating expected utility by a function of mean and variance', American Economic Review, Vol. 69, No. 3, pp.308-317.

Lintner, J. (1965) 'The valuation of risk assets and the selection of risky investments in stock portfolios and capital budgets', Review of Economics and Statistics, Vol. 47, pp.13-37.

Markowitz, H. (1959) Portfolio Selection: Efficient Diversification of Investments, Cowles, Foundation Monograph \#16, Wiley, New York.

Markowitz, H.M. (1999) 'The early history of portfolio theory: 1600-1960', Financial Analysts Journal, July/August, Vol. 55, No. 4.

Marschak, J. (1938) 'Money and the theory of assets', Econometrica, Vol. 6, pp.311-325.

McAleer, M. (2005) 'Automated inference and learning in modelling financial volatility', Econometric Theory, Vol. 21, pp.232-261.

McAleer, M. and Medeiros, M. (2008) 'Realized volatility: a review', Econometric Reviews, Taylor and Francis Journals, Vol. 27, Nos. 1-3, pp.10-45.

Merton, R.C. (1973) 'Theory of rational options pricing', Bell Journal of Economics and Management Science, Vol. 4, pp.141-183.

Mossin, J. (1966) 'Equilibrium in a capital asset market', Econometrica, Vol. 34, pp.768-783.

Nelson, D. (1991) 'Conditional heteroskedasticity in asset returns: a new approach', Econometrica, Vol. 59, pp.347-370.

Pflug, G. (2000) 'Some remarks on value-at-risk and conditional-value-at-risk', chapter in Probabilistic Constrained Optimisation, S. Uryasev (Ed.), Kluwer Academic Publishers, Dordrecht, Boston.

Poon, S.H. and Granger, C.W.J. (2003) 'Forecasting volatility in financial markets: a review', Journal of Economic Literature, Vol. 41, No. 2, pp.478-539.

Poon, S.H. and Granger, C.W.J. (2005) 'Practical issues in forecasting volatility', Financial Analysts Journal, Vol. 61, No. 1, pp.45-56.

Ramsey, F.P. (1926) 'Truth and probability', in Ramsey (1931), The Foundations of Mathematics and other Logical Essays, Ch. 7, p.156-198, edited by R.B. Braithwaite, Kegan, Paul, Trench, Trubner \& Co., London, Harcourt, Brace and Company, New York.

Roy, A.D. (1952) 'Safety first and the holding of assets', Econometrica, Vol. 20, pp.431-449.

Rubinstein, M. (2002) 'Markowitz's portfolio selection: a fifty year retrospective', The Journal of Finance, Vol. 57, No. 3, pp.1041-1045.

Sharpe, W.F. (1964) 'Capital asset prices: a theory of market equilibrium under conditions of risk', Journal of Finance, Vol. 19, pp.425-442.

Tobin, J. (1958) 'Liquidity preference as behaviour towards risk', Review of Economics Studies, Vol. 25, pp.65-86.

Uryasev, S. and Rockafellar, R.T. (1999) 'Optimisation of conditional value-at-risk', available at www.ise.ufl.edu/uryasev/CVar1_JOR.pdf.

Von Neumann, J. and Morgenstern, O. (1947) The Theory of Games and Economics Behaviour, 2nd ed., Princeton UP, Princeton, NJ.

Whaley, R.E. (2009) 'Understanding the VIX', The Journal of Portfolio Management, Spring, Vol. 35, No. 3. 